\title{
Reestruturação do Curso de Formação em Conselhos Escolares no AVA Moodle por meio do Design Instrucional
}

\author{
Eliana A. M. Leite ${ }^{1}$, Gilvandenys L. Sales ${ }^{2}$, Herbert V. Lima ${ }^{1}$, Eveline P. S. Aguiar ${ }^{2}$ \\ ${ }^{1}$ Instituto Universidade Virtual - Universidade Federal do Ceará \\ Campus do Pici - CEP: 60040-531 - Fortaleza - CE - Brasil \\ ${ }^{2}$ Diretoria de Educação a Distância - Instituto Federal do Ceará (IFCE) \\ Av. Treze de Maio, 2081, Benfica - CEP: 60040-531 - Fortaleza - CE - Brasil \\ denyssalesdifce.edu.br, elimoreiraeadegmail.com, \\ herbertevirtual.ufc.br, evelineportodifce.edu.br
}

\begin{abstract}
Presents the restructuring of a course in e-learning, through an Instructional Design Matrix (Matrix DI), applied to the Training Course for School Boards supported by the Ministry of Education (MEC) under Department of Basic Education (SEB). The methodology involved discussion forums structured theme generator and guiding questions and quizzes designed to enforce an assessment assisted with their feedback regulators. It was used as an assessment tool Vectors Learning Model (Model LV). The results show a reduction in dropout and lower workload of tutors in order that the classes were numerous.
\end{abstract}

Resumo. Apresenta-se a reestruturação de um curso em EaD online, por meio de uma Matriz de Design Instrucional (Matriz DI), aplicado ao Curso de Formação em Conselhos Escolares oferecido e apoiado pelo Ministério da Educação (MEC) no âmbito da Secretaria de Educação Básica (SEB). A metodologia envolveu fóruns de discussão estruturados com tema gerador e questionamentos norteadores e quizzes planejados para fazer valer uma avaliação assistida com seus feedbacks reguladores. Empregou-se como ferramenta de avaliação o Modelo Learning Vectors (Modelo LV). Os resultados revelam uma redução da evasão e menor sobrecarga de trabalho dos tutores tendo em vista que as turmas eram numerosas.

\section{Introdução}

Analisando dados da Pesquisa Nacional por Amostra de Domicílios (PNAD, 2011), que trata da evasão escolar, o contingente de crianças e jovens fora da escola no Brasil em 2011 era, aproximadamente, de 1 milhão de crianças de 4 e 5 anos na Educação Infantil, 0,5 milhão de crianças e adolescentes no Ensino Fundamental e 1,6 milhão de jovens de 15 a 17 anos do Ensino Médio. Ou seja, passam de 3 milhões o número dos "Sem Escola" em nosso país. Em termos comparativos isto equivale a uma população de uma grande cidade ou de um pequeno país como o Uruguai.

Relativo à efetivação de uma gestão democrática na escola, a Pesquisa de Informações Básicas Municipais, segundo o IBGE (2011), atesta que, apenas 76,2\% dos municípios brasileiros possuem Conselhos Escolares. Este colegiado, em termos legais, tem como objetivo atuar efetivamente no sentido de promover práticas democráticas e participativas, oportunizando discussões e reflexões para o benefício da comunidade escolar (VASCONCELOS et al., 2013, p.335). 
Quanto ao investimento em educação, dados revelam que o gasto anual por estudante do Ensino Fundamental ao Superior, é um dos menores numa escala que reuniu 36 países desenvolvidos e em desenvolvimento. Ganhamos apenas da África do Sul e Indonésia, e a nossa frente destacam-se o Chile, Argentina e México (OCDE, 2012).

Na contramão destes números, ações têm sido estabelecidas visando a melhoria da qualidade da Educação Básica como o Plano Nacional de Alfabetização na Idade Certa (PNAIC), que levou diretamente à Escola o Programa de Alfabetização na Idade Certa (PAIC) e com isso, num futuro próximo, espera-se reduzir problemas de desmotivação e evasão da sala de aula.

Outra ação que impacta diretamente a Escola Pública é o Programa Nacional de Fortalecimento dos Conselhos Escolares, vinculado ao Ministério da Educação (MEC) e à Secretaria de Educação Básica (SEB) que oferece semestralmente em duas fases o Curso de Formação Continuada em Conselhos Escolares em todo território nacional.

Neste trabalho, apresenta-se a reestruturação do curso em EaD online, Curso de Formação Continuada em Conselhos Escolares (CFCCE), por meio de uma Matriz de Planejamento Pedagógico e Design Instrucional (Matriz DI).

Este curso tem foco na gestão democrática e participativa de todos os que fazem a escola. Sua meta é formar e capacitar dirigentes e técnicos das secretarias municipais e estaduais de educação e conselheiros escolares dos estados do Amazonas, Acre, Amapá, Ceará, Maranhão, Mato Grosso do Sul, Pará, Roraima, Rondônia e Tocantins. Por fim, sua finalidade maior é: a melhoria da qualidade da escola pública.

Reestruturar exige o planejar. Para Vasconcellos (2000, p. 35): "Planejar é antecipar mentalmente uma ação a ser realizada e agir de acordo com o previsto; é buscar fazer algo incrível, essencialmente humano: o real ser comandado pelo ideal".

Libâneo (1993, p. 221) acrescenta que:

O planejamento é uma tarefa docente que inclui tanto a previsão das atividades didáticas em termos da sua organização e coordenação em face de objetivos propostos, quanto a sua revisão e adequação no decorrer do processo de ensino.

Vasconcellos (2000, p. 80) reitera: que "o planejamento é o processo contínuo e dinâmico de reflexão, de tomada de decisão, colocação em prática e de acompanhamento".

O simples ato de pensar como estruturar um curso em EaD online para um ambiente virtual já revela detona o processo do planejar. Desta forma, este artigo encontra-se organizado da seguinte forma: a seguir, discorre-se sobre o Programa Nacional de Fortalecimento dos Conselhos Escolares e o Curso de Formação Continuada em Conselhos Escolares, como também, a metodologia que emprega o Modelo LV de avaliação; na seção 3 trata-se da Matriz DI e do planejamento do curso; na seção 4 apresentam-se os resultados dos cursistas incluindo a evasão e, finalmente, são apresentadas as considerações finais e possibilidades para trabalhos futuros. 


\section{O Programa Nacional de Fortalecimento dos Conselhos Escolares e o Curso de Formação Continuada em Conselhos Escolares}

O Programa Nacional de Fortalecimento dos Conselhos Escolares (PNFCE), criado em 2004 no âmbito da Secretaria de Educação Básica do Ministério da Educação, é uma das principais ações do Estado brasileiro no campo da formação de pessoal para uma gestão democrática das escolas públicas brasileiras.

(...) Uma das características da democracia é o compartilhamento das decisões e informações. Compartilhar significa envolver pais, alunos, professores, funcionários e outras pessoas da comunidade na administração escolar. O Conselho Escolar tem se mostrado importante instrumento de prática da gestão democrática. (VASCONCELOS et al., 2013, p.335)

Entre as ações do referido Programa, universidades públicas unem-se na oferta do Curso de Formação Continuada em Conselhos Escolares (CFCE), que é um curso de extensão universitária destinado à formação de conselheiros escolares, como também técnicos das secretarias estaduais e municipais de educação, com um fim único: o fortalecimento dos Conselhos Escolares.

Dentre estas instituições de ensino superior públicas, esta pesquisa toma como alvo a Universidade Federal do Ceará (UFC) que atua nas regiões Norte, Nordeste e Centro-Oeste, que e tem promovido a formação em Conselho Escolar uma média de 500 cursistas semestralmente de forma crítica e reflexiva acerca das questões na condução de uma gestão democrática e participativa da escola. Sendo assim, esta instituição tem contribuído para a valorização deste colegiado, pois bem se sabe que:

Embora os Conselhos Escolares tenham sido criados no final dos anos 1980
ainda hoje se enfrenta o problema da não existência deste colegiado em
muitas escolas brasileiras e da restrita participação dos conselheiros na
administração da escola, por conta de gestões centralizadas na figura do
diretor e da cultura da não participação. (VASCONCELOS et al., 2013,
p.225)

Construir uma democracia participativa no âmbito da escola torna esta instituição realmente pública. Dessa forma

(...) os Conselhos Escolares são a instância de poder local, no âmbito da escola, que têm como principal missão publicizar a escola pública. Torná-la efetivamente pública. Isto, a partir do ingresso e da discussão, em seu corpo, dos diversos pontos de vista e concepções presentes (...) (IDEM, 2013, p.154)

\subsection{A Metodologia do Curso de Formação Continuada em Conselhos Escolares}

No início do curso o aluno participa do Módulo de Ambientação, onde este discente conhece as ferramentas que irá utilizar ao longo do curso. O conteúdo programático é desenvolvido em 5 módulos didáticos. Em cada módulo o cursista participa de um Fórum de discussão e de um Quiz. No final, o cursista deve apresentar um trabalho a título de conclusão intitulado "Plano Inicial" e/ou "Plano de Ação", respectivamente para cursistas da Fase 1 e Fase 2.

A metodologia do curso adota uma recuperação paralela ao final de cada módulo, bem como, outra recuperação ao final do curso, denominada "Ajustando os Ponteiros". A intenção desta recuperação é capacitar o maior número possível de cursistas e oportunizar aprendizagens. 
O planejamento e execução do trabalho de transposição do conteúdo, anteriormente ofertado no ambiente virtual Moodle disponibilizado em sítio ${ }^{1}$ do MEC, e atualmente ofertado em sítio da universidade alvo desta pesquisa, contou com a elaboração de uma Matriz de Planejamento Pedagógico e Design Instrucional (Matriz DI), onde se detalhou todas as ações e atividades do curso, incluindo metodologias de interação e de avaliação.

Adota-se no referido curso o sistema acadêmico gerenciado pelo Modelo Learning Vectors (Modelo LV), que é um modelo de suporte e gerenciamento à avaliação formativa concebido para automatizar o acompanhamento qualitativo/quantitativo de alunos em Ambientes Virtuais de Aprendizagem - AVA. (SALES, 2010)

O Modelo LV (Figura 1) prima por uma metodologia fundamentada na interação mediada por ícones e menções qualitativas atribuídas pelo professor-tutor. Faz-se uso de vetores e de equações trigonométricas na especificação da solução tecnológica, por entender que processos lineares não coadunam com uma avaliação mais voltada para uma pedagogia diferenciada e progressista.

A opção pelo uso de vetores para a especificação do modelo de avaliação LV permite associar valores numéricos na forma bidimensional. A cada uma destas dimensões associam-se aspectos bem definidos que, devidamente trabalhados, mostram-se necessários ao pleno exercício de uma avaliação comprometida com o caráter formativo e de regulagem das aprendizagens. (IDEM, 2010, p.86).

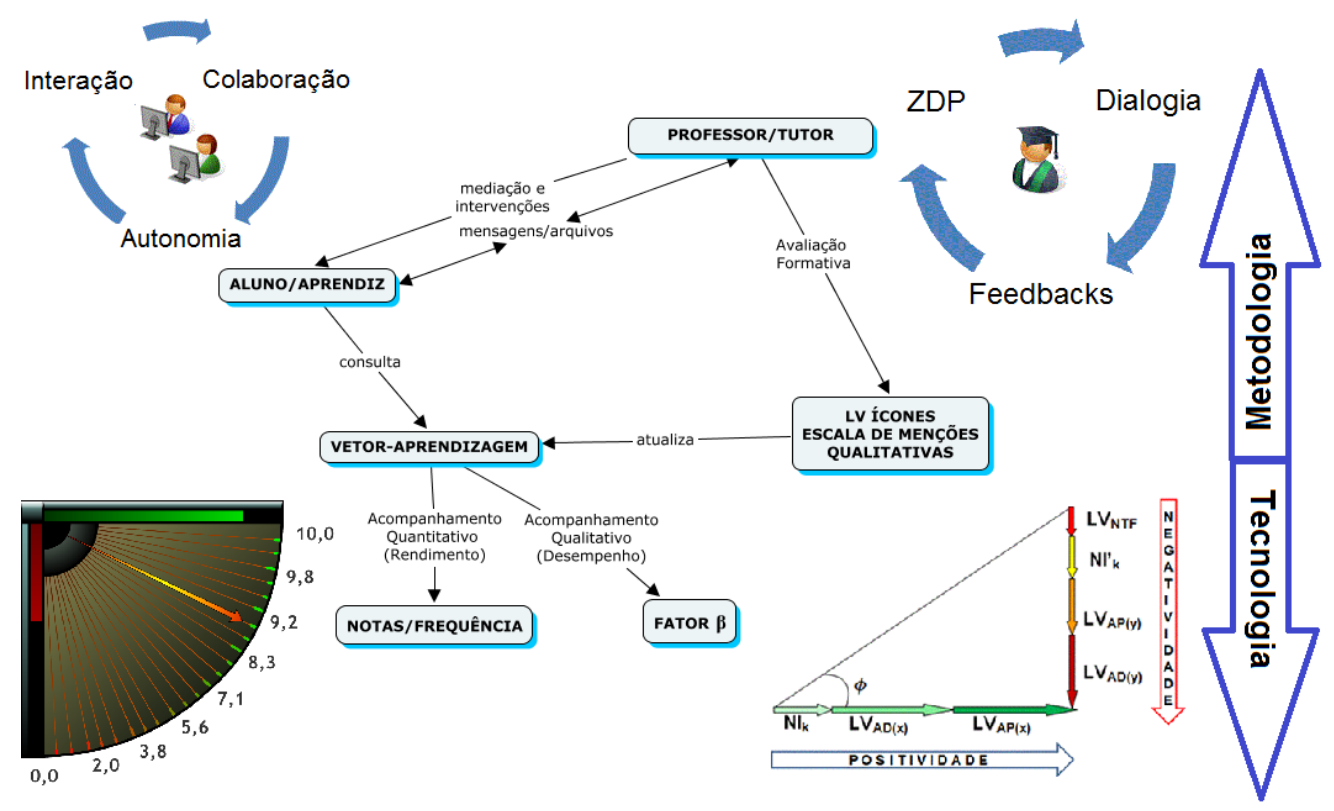

Fonte: Adaptado de Sales (2010)

Figura 1. O Modelo LV

No Modelo LV adota-se uma escala de ícones (Figura 2) associada à menções qualitativas macros: Muito Bom, Bom, Regular, Não Satisfatório e Insuficiente, que por

${ }^{1}$ http://conselhoescolar.mec.gov.br 
sua vez associam-se a critérios subjacentes de menor escala, representados por tonalidades de cor da categoria macro. Desta forma, ficam estabelecidos dois critérios para a avaliação, sejam nas mensagens nos fóruns ou arquivos de portfólio.

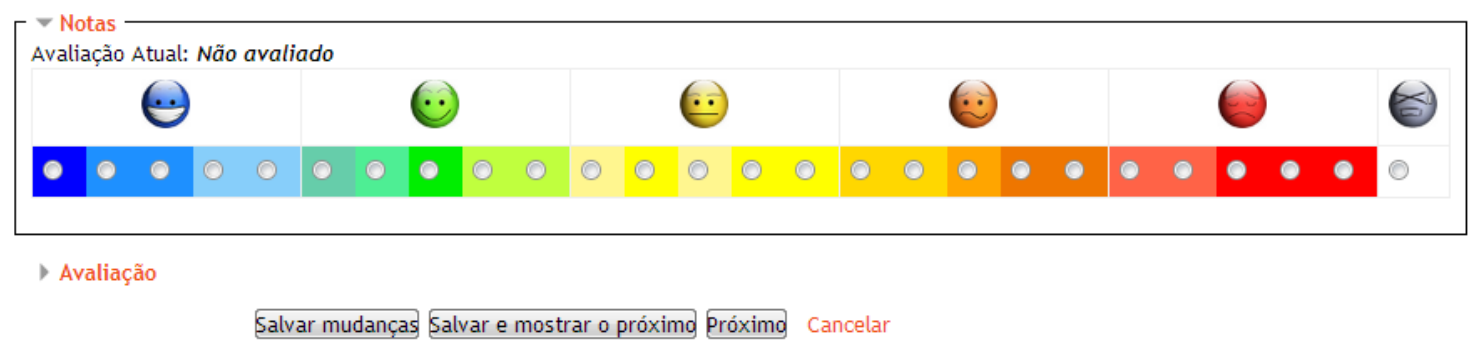

Figura 2. A Escala de Ícones do Modelo LV aplicada ao Moodle

O cursista pode acompanhar suas notas ao longo do curso por meio da tabela de notas fornecida pelo plugin desenvolvido para atender o Modelo LV, bem como, os tutores podem fazer avaliação diagnóstica ao longo de todo processo de duração do curso (Figura 3).

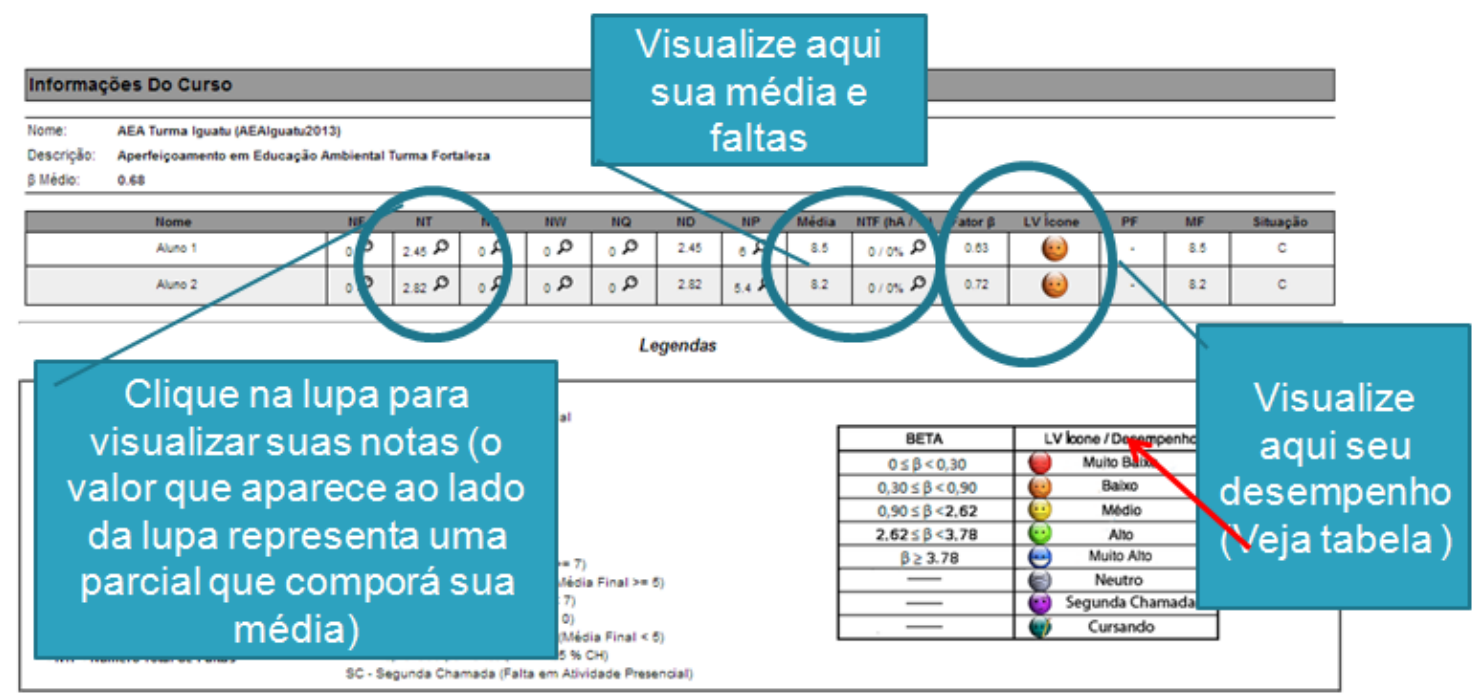

Figura 3. A Tabela de Notas do Moodle fornecida pelo plugin LV

O curso é basicamente composto por fóruns e quizzes. A metodologia nos fóruns é propor um tema central e gerador da discussão reforçado por questionamentos norteadores. Cada cursista deve enviar, no mínimo, duas inserções para garantir sua nota máxima em cada fórum, sendo uma de resposta ao tema central e outra de interação com os demais participantes do curso.

Os quizzes alinham-se à metodologia da avaliação assistida. A "avaliação assistida é um ato processual, dinâmico e interativo em que processos de mediação possibilitam modificações e plasticidade nas estruturas cognitivas" (FEUERSTEIN, KLEIN e TANNENBAUM, 1994, 1997). Em sua elaboração são usados os cadernos do curso $^{2}$ na criação de questões de múltipla escolha, associação, completar lacunas, alternativas de verdadeiro ou falso e dissertativas. Cada quiz oferece a oportunidade do cursista realizar até 3 tentativas e permanece aberto no Moodle enquanto durar o módulo.

\footnotetext{
${ }^{2}$ Disponíveis em: http://conselhoescolar.virtual.ufc.br/index.php/biblioteca-virtual?id=28
} 
Para Leite et al. (2011) esta avaliação é assistida quando feedbacks reguladores estão presentes no processo e ajudam o aluno a aprender. Nesse sentido

\begin{abstract}
a avaliação assistida ou dinâmica para uso em ambientes virtuais de aprendizagem poderá contribuir para que a aprendizagem se processe de forma dinâmica, desde que o professor seja um facilitador do processo de aprendizagem desse aluno por meio dos feedbacks e colabore para que o aluno consiga regular sua própria aprendizagem percebendo os conteúdos que precisam melhorar e os quais já conseguiu aprender.
\end{abstract}

\title{
3. A Matriz de Planejamento Pedagógico e Design Instrucional (Matriz DI)
}

No início do planejamento e execução do trabalho de reestruturação do curso definiu-se um modelo de desenvolvimento de design instrucional a partir do proposto por Filatro (2007), que aplica uma estrutura em espirais, o que permite acrescentar sempre mais detalhes e abre-se constantemente a revisões daquilo já feito.

A Matriz DI consta de um documento onde são agendadas as atividades síncronas e/ou assíncronas, presenciais ou a distância, avaliáveis ou não, às quais se atribuem um determinado peso por sua significância, definida por um percentual relacionado à importância da atividade relativamente ao curso como um todo. (SALES, 2010)

\begin{abstract}
As definições desses pesos para cada atividade virtual ou presencial devem ser apresentadas em um documento desenvolvido no ato de criação e configuração de um curso pelos especialistas em conteúdos, professores formadores e/ou tutores que ministrarão o curso, momento no qual são planejadas todas as atividades presenciais e a distância a serem configuradas no AVA (IDEM, 2010, p.87)
\end{abstract}

Os fóruns avaliativos foram planejados num total de cinco, um para cada módulo. Na Tabela 1 apresenta-se o modelo utilizado na Matriz DI.

Tabela 1. Modelo de Fórum aplicado ao curso CFCE

\begin{tabular}{|l|l|}
\hline \multicolumn{1}{|c|}{ Fórum do Módulo 3 } & $\begin{array}{l}\text { Tipo: } \\
\text { ( x) Única Discussão } \\
\text { Concepções de conhecimento na escola e diversidade cultural }\end{array}$ \\
\begin{tabular}{ll} 
( ) Geral \\
Com base no Caderno 3, reflita sobre a seguinte indagação: \\
$\begin{array}{l}\text { Quais os conceitos de pessoa, de sociedade e de educação que } \\
\text { norteiam a prática democrática da gestão da escola? }\end{array}$ \\
$\begin{array}{l}\text { Para discutir esta questão de forma reflexiva, procure responder antes } \\
\text { acerca dos seguintes questionamentos norteadores: }\end{array}$ & $\begin{array}{l}\text { ( ) Sem Nota } \\
\text { ( ) Nota Média }\end{array}$ \\
$\begin{array}{l}\text { a) Qual a importância de haver tolerância entre as pessoas e grupos } \\
\text { sociais (processos emancipatórios)? }\end{array}$ & $\begin{array}{l}\text { No Mínimo de } \\
\text { b) Por quais motivos é injustificável a imposição de valores e/ou } \\
\text { conhecimentos de uma pessoa ou de um grupo social sobre outra(o) } \\
\text { utilizando-se de opressão ideológica? }\end{array}$ \\
$\begin{array}{l}\text { c) Como o Conselho Escolar pode contribuir para o respeito e a } 1 \\
\text { valorização do saber e da cultura do(a) estudante e da comunidade? } \\
\text { (clique aqui e leia acerca das Orientações para participar em Fóruns) }\end{array}$ & $\begin{array}{l}\text { (x) } 2 \\
\text { ( ) } 6\end{array}$ \\
\hline \multicolumn{2}{|c|}{ Bons Estudos e Boa Discussão! 10} \\
Peso: $8 \%$
\end{tabular} \\
\hline
\end{tabular}

Os quizzes, num total de seis, cinco avaliativos e 1(um) apenas de ambientação, foram inicialmente desenvolvidos numa matriz (Tabela 2) que continha as assistências aos cursistas no intuito de fazer deste instrumento um canal de aprendizagens.

Tabela 2. Modelo de Quiz aplicado ao curso CFCE 


\begin{tabular}{|c|c|c|c|}
\hline \multicolumn{4}{|c|}{ 1.Tipo de Questão: Múltipla Escolha com Múltiplas Respostas Corretas } \\
\hline \multicolumn{4}{|c|}{$\begin{array}{l}\text { Nome da Pergunta: Módulo 2/Caderno 6/Fase 2/Questão de Múltipla Escolha com Múltiplas Respostas } \\
\text { Corretas } \\
\text { Texto da Pergunta: } \\
\text { A atuação do Conselho exige processos democráticos e cidadãos no próprio processo de formação de seus } \\
\text { membros. Tal processo foi experimentado na experiência dos Círculos de Cultura. A metodologia do } \\
\text { Círculo de Cultura é um processo de produção participativa do saber e da cultura e tem suas origens nas } \\
\text { contribuições deixadas por Paulo Freire. Nesse sentido assinale aspectos importantes que definem a } \\
\text { lógica dos Círculos de Cultura: }\end{array}$} \\
\hline & Alternativas ou Escolhas & Nota \% & Feedback \\
\hline 1 & A conviviabilidade & 33 & $\begin{array}{l}\text { Muito bem! Saiba que o Círculo de } \\
\text { Cultura apoia-se no pressuposto de } \\
\text { que ninguém consegue ser só, isolado } \\
\text { no mundo. Parte do entendimento de } \\
\text { que o homem é um ser } \\
\text { eminentemente social e, como } \\
\text { afirmou Paulo Freire, que o homem só } \\
\text { consegue ser na medida em que } \\
\text { outros homens também o são. }\end{array}$ \\
\hline 2 & $\begin{array}{l}\text { Relações de 'ensinação', ou seja, aquelas } \\
\text { que fazem com que no grupo um fale e os } \\
\text { outros ouçam submissamente. }\end{array}$ & nenhum & $\begin{array}{l}\text { Afirmação falsa sim!!! O que se } \\
\text { aprende nos Círculos de Cultura é } \\
\text { ouvir o outro, a posicionar-se bem, a } \\
\text { tratar os conflitos de interesses } \\
\text { entendendo suas origens sociais, } \\
\text { políticas, afetivas, econômicas, } \\
\text { étnicas etc. O diálogo ajuda, também, } \\
\text { na construção de alianças e na } \\
\text { identificação de parceiros. O diálogo } \\
\text { leva os participantes a desenvolverem } \\
\text { uma atitude reflexiva, a aprender a } \\
\text { formular boas perguntas e a respondê-- } \\
\text { las com a ajuda do coletivo. }\end{array}$ \\
\hline 3 & Ação dialógica & 33 & $\begin{array}{l}\text { Conforme Paulo } \text { Freire afirma, } \\
\text { comunicação e e convivência } \\
\text { favorecem a comunhão e a busca. }\end{array}$ \\
\hline 4 & Investigação coletiva & 34 & $\begin{array}{l}\text { Muito bem!!! No Círculo de Cultura } \\
\text { os participantes são estimulados ao } \\
\text { exercício pedagógico de leitura da } \\
\text { realidade sociopolítica da escola e da } \\
\text { sociedade e a compreensão dessa } \\
\text { temática passa a ser o desafio de todos } \\
\text { que integram o Círculo. }\end{array}$ \\
\hline 5 & A verticalização das relações & nenhum & $\begin{array}{l}\text { É exatamente o oposto! O Círculo } \\
\text { facilita a construção de pessoas mais } \\
\text { coletivas porque estimula a } \\
\text { horizontalização das relações entre os } \\
\text { participantes do grupo de estudo, } \\
\text { favorecendo, dessa forma, a } \\
\text { instalação de um ambiente } \\
\text { cooperativo, colaborativo, interativo, } \\
\text { onde germinam relações de } \\
\text { solidariedade e a noção da coisa } \\
\text { pública. }\end{array}$ \\
\hline
\end{tabular}


Consideraram-se potenciais cursistas aqueles que de alguma forma apresentaram sua intenção de fazer o curso; esse total perfez 1026 cursistas. Por outro lado, apenas 831 fizeram seu primeiro acesso e chegaram ao final do módulo 1.

Ao final do Módulo 1 observou-se uma média de 19,3\% de evasão no total de cursistas, sendo inferior para a Fase 2 e um pouco acima deste valor para a Fase 1. Isto se justifica pelo fato dos alunos da Fase 2 já terem realizado este curso anteriormente, como também, sua familiaridade com a metodologia; embora esta tenha sido modificada.

Tabela 3. Resultados ao final do Módulo 1

\begin{tabular}{|c|c|c|c|c|c|c|c|}
\hline \multicolumn{2}{|c|}{ TURMA } & $\begin{array}{l}\text { Potenciais } \\
\text { Cursistas }\end{array}$ & $1^{\circ}$ Acesso* & Cursistas** & $\% * * *$ & $\% * * * *$ & Evasão \\
\hline \multirow{8}{*}{ 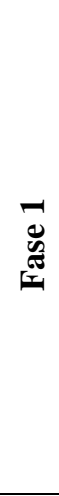 } & 1 & 82 & 63 & 50 & 61,0 & 79,4 & 20,6 \\
\hline & 2 & 81 & 54 & 33 & 40,7 & 61,1 & 38,9 \\
\hline & 3 & 84 & 70 & 51 & 60,7 & 72,9 & 27,1 \\
\hline & 4 & 85 & 53 & 42 & 49,4 & 79,2 & 20,8 \\
\hline & 5 & 80 & 49 & 35 & 43,8 & 71,4 & 28,6 \\
\hline & 6 & 80 & 64 & 51 & 63,8 & 79,7 & 20,3 \\
\hline & 7 & 85 & 64 & 55 & 64,7 & 85,9 & 14,1 \\
\hline & 8 & 82 & 80 & 71 & 86,6 & 88,8 & 11,3 \\
\hline \multirow{6}{*}{ 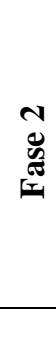 } & 9 & 67 & 62 & 50 & 74,6 & 80,6 & 19,4 \\
\hline & 10 & 74 & 70 & 67 & 90,5 & 95,7 & 4,3 \\
\hline & 11 & 77 & 77 & 69 & 89,6 & 89,6 & 10,4 \\
\hline & 12 & 74 & 70 & 58 & 78,4 & 82,9 & 17,1 \\
\hline & 13 & 75 & 55 & 45 & 60,0 & 81,8 & 18,2 \\
\hline & TOTAL & 1026 & 831 & 677 & 66,0 & 81,5 & 19,3 \\
\hline \multicolumn{8}{|c|}{ *Alunos que iniciaram o curso } \\
\hline \multicolumn{8}{|c|}{ **Alunos efetivamente Cursando ao final do Módulo 1} \\
\hline \multicolumn{8}{|c|}{ ***Percentual de cursistas relativo ao $\mathrm{N}^{\circ}$ de Matriculados } \\
\hline \multicolumn{8}{|c|}{ ****Percentual de cursistas relativo aqueles que fizeram o $1^{\circ}$ acesso } \\
\hline
\end{tabular}

Ao final do curso os resultados estão apresentados na Tabela 4. Observa-se que um total de 573 alunos concluiu com êxito, representando um total de $69 \%$ dos cursistas.

Tabela 4. Resultados ao final do curso

\begin{tabular}{|c|c|c|c|r|c|c|}
\hline \multicolumn{2}{|c|}{ TURMA } & $\mathbf{1}^{\mathbf{0}}$ Acesso* & Recuperação*** & Fator $\boldsymbol{\beta}$ & Aprovados & \% \\
\hline \multirow{4}{*}{} & 1 & 63 & 60 & 1,33 & 38 & 60,3 \\
\cline { 2 - 7 } & 2 & 54 & 65 & 0,53 & 22 & 40,7 \\
\cline { 2 - 7 } & 3 & 70 & 76 & 1,16 & 49 & 70,0 \\
\hline \multirow{5}{*}{} & 4 & 53 & 68 & 0,83 & 37 & 69,8 \\
\cline { 2 - 7 } & 5 & 49 & 68 & 1,02 & 31 & 63,3 \\
\hline & 6 & 64 & 51 & 1,77 & 44 & 68,8 \\
\hline
\end{tabular}




\begin{tabular}{|c|c|c|c|c|c|c|}
\hline & 7 & 64 & 56 & 1,21 & 45 & 70,3 \\
\hline & 8 & 80 & 38 & 2,14 & 60 & 75,0 \\
\hline \multirow{5}{*}{$\begin{array}{l}N \\
\tilde{D} \\
\tilde{E} \\
\tilde{E}\end{array}$} & 9 & 62 & 37 & 2,19 & 49 & 79,0 \\
\hline & 10 & 70 & 31 & 2,08 & 57 & 81,4 \\
\hline & 11 & 77 & 38 & 2,38 & 64 & 83,1 \\
\hline & 12 & 70 & 50 & 1,62 & 39 & 55,7 \\
\hline & 13 & 55 & 59 & 1,10 & 38 & 69,1 \\
\hline & TOTAL & 831 & 697 & - & 573 & 69,0 \\
\hline
\end{tabular}

Outro fator importante a ser apresentado é o Fator $\beta$, métrica qualitativa associada ao Modelo LV, que se associa à qualidade da interação e à frequência do cursista. Desta forma, comprova-se que as turmas 8 e 11, respectivamente da Fase 1 e Fase 2, por apresentarem o maior Fator $\beta$ médio de suas turmas tiveram o maior número de aprovados.

A satisfação dos cursistas pode ser analisada pelas palavras de um destes a seguir:

Aprendi muito com o que cada um sem exceção, deixou escrito nos Fóruns de participação. Espero que os conhecimentos adquiridos nesta formação seja de fato, em nossas mãos, uma importante ferramenta de transformação social. Quero em especial, agradecer à nossa Tutora (...). Graças a pessoas como você, é que descobrimos em nós, forças capazes de mudar nossa vida e a vida de toda uma comunidade. (Cursista CFCE - 2013.1)

\section{Considerações Finais}

Em EaD online quanto maior o comprometimento do tutor, interagindo e avaliando, menor é a evasão e, possivelmente, maior é a motivação dos cursistas. Pois, em turmas assim constata-se a maior quantidade de alunos que realizam os quizzes e que também participam dos fóruns.

O acompanhamento de notas pelo sistema de controle acadêmico, segundo o Modelo LV, conferiu ao Professor-Tutor menor sobrecarga de trabalho, uma vez que este profissional tem a seu dispor e a qualquer tempo ao longo do curso, a automação do controle de notas e frequência, gerando ao final do curso um arquivo com a situação final do cursista no próprio sistema.

Para trabalhos futuros sugere-se diversificar mais as atividades propostas e analisar os efeitos sobre a evasão.

\section{Referências bibliográficas}

FILATRO, A. Design instrucional: educação e tecnologia. $2^{\mathrm{a}}$ ed. São Paulo: Editora Senac, 2007. 215 p.

FEUERSTEIN R.; KLEIN, P. S.; TANNENBAUM A. J. (1994). Mediated learning experience (MLE): Theoretical, Psychosocial And Learning Implications. London: Freund.

Teoria de la Modificabilidad Cognitiva Estructural (1997). In: Es modificable la inteligencia? Madrid: Editora Bruno. 
LEITE, E. A. M., SALES, G. L., SOUSA, L. L. R. de, Joye, C. R. Avaliação Assistida, Feedbacks e Questionários do Moodle. In: Workshop sobre Avaliação e Acompanhamento da Aprendizagem em Ambientes Virtuais. 22 $2^{\circ}$ Simpósio Brasileiro de Informática na Educação. Anais... São Paulo, SBC, 2011.

LIBÂNEO, José Carlos. Didática. Coleção magistério $-2^{\circ}$ grau. Série formação do

SALES, G. L. (2010). Learning Vectors (LV): um modelo de avaliação da aprendizagem em EaD online aplicando métricas não-lineares. Tese Doutorado. Departamento de Engenharia de Teleinformática. Universidade Federal do Ceará. 2010. 239f.

e Soares, J. M. (2007). Learning Vectors: Um Instrumento de Avaliação Online Como Suporte a Aprendizagem Colaborativa em Ambientes Virtuais de Aprendizagem. In: Workshop sobre Avaliação e Acompanhamento da Aprendizagem em Ambientes Virtuais. Anais... São Paulo.

e Soares, J. M. (2012). Learning Vectors (LV): Um Modelo de Avaliação Processual com Mensuração Não-Linear da Aprendizagem em EaD online. Revista Brasileira de Informática na Educação, Volume 20, Número 1.

VASCONCELLOS C. dos S. Planejamento: projeto de ensino-aprendizagem e projeto político-pedagógico. São Paulo, Libertad, 2000.

VASCONCELlOS, F. H. L., SOARES, S. P. L., MARTins, C. A., AGUiAR, C. M. S. (Organizadores). Conselho Escolar: processos, mobilização, formação e tecnologia. Editora da Universidade Federal do Ceará - UFC, Fortaleza, Ceará, 2013. 